\title{
Research on the Practical Teaching System Reform of Public Administration Specialties in the Context of New Liberal Arts
}

\author{
ZHENG Yong-ping ZHANG Ruo-Nan \\ (College of Public Administration, College of Jinshan, Fujian Agriculture and Forestry University)
}

\begin{abstract}
The ideas and measures of promoting the practical teaching system reform of public administration specialties of Fujian agricultural and Forestry University in the context of novel liberal arts are analyzed in this paper. To fulfill the requests of practice orientation, cross domain learning and integrated application proposed by the novel liberal arts, the practical teaching system of public administration should stick to the major direction of cultivating "public management" talents, consolidate the foundation for development and foster the comprehensive thinking ability of talents under the guidance of "public spirit", and improve their innovation ability and professional qualities on the basis of "governance capacity". The specific measures include optimizing the professional talents cultivation plan, building the teaching experiment and practice platform, developing the specialties comprehensive practice platform, lifting the innovative guidance ability of teachers, and improving the design of practical teaching mechanism.
\end{abstract}

Keywords: novel liberal arts, public administration, practical teaching

\section{Introduction}

The Ministry of Education decided to implement the plan 2.0 to cultivate excellent engineers, doctors, agricultural and forestry talents, teachers, legal talents, news communication talents and top students of fundamental subjects, and make a request of comprehensively promoting the "construction of novel liberal arts" in October, 2018 [1]. More than 50 experts from all over the country gathered in Shandong University on August 20, 2019 to take part in the symposium on the construction of novel liberal arts in colleges and universities, and had an in-depth discussion reached a consensus on the connotation and development path of the novel liberal arts construction. The novel liberal arts center on practice orientation, cross domain learning and comprehensive application. How to grasp the common requirements of economic and social development for the cultivation of public management talents in a forward-looking way, and achieve the transformation of the cultivation mode of public management talents through practical teaching system reform? In this paper, the context of the practical teaching reform and development of public administration specialties of Fujian agricultural and Forestry University is analyzed, the needs and direction of the reform are explored, and the measures of optimizing the professional talents cultivation plan, building the teaching experiment and practice platform, developing the specialty comprehensive practice platform, lifting the innovative guidance ability of teachers, and improving the design of practical teaching mechanism are proposed mainly based on the effective combination of the practical teaching system of public administration specialties and the social development in the context of novel liberal arts.

\section{Analysis of the Background of Practical Teaching System Reform for Public Administration Specialties}

\subsection{Analysis of the Reform and Development of Public Administration Promoted by Novel Liberal Arts}

Public administration is a discipline that studies the management activities of public organizations and their rules by the integrated use of multi-disciplinary theories 
and methods of political science, economics, management science, sociology and organization theory [2]. It has strong social practicality. To fulfill the strategies of "building a service-oriented government with which people are satisfied" and "modernizing the national governance system and capabilities" put forward by the report of the 19th National Congress, high-level and applied public management talents with complicate skills and innovative mind are urgently needed. Compared with traditional liberal arts, novel liberal arts emphasize more on cross fusion and practical application to meet the demands of new economy, new era and new society. The cultivation of high-level and applied public management talents with complicate skills and innovative mind accords with the requirements for talent training put forward by the novel liberal arts construction and highlights the practice orientation, cross domain learning and comprehensive application proposed by novel liberal arts. As for the practice of management discipline, the talents trained should be transformed from "management type" to "governance type". Based on the requirements of the modernization of national governance system and governance capacity, the learning and practice of public administration should emphasize the innovation of management content, as well as the integration, flexibility and networking of management methods.

\subsection{Analysis of the Construction Background and Foundation of Public Administration Specialties}

The College of Public Administration, Fujian Agriculture and Forestry University sets up one secondary discipline doctoral program, one primary discipline master program and two professional master degree programs, and have undergraduate programs such as public administration specialties (including Public Affair Management, Public Administration, Labor and Social Security, etc.), Land Resources Management, Law, etc. At present, the College of Public Administration has 6 national and provincial platforms including Fuzhou branch of National Public Management Case Center, 18 national and provincial rural fixed observation spots, 57 practice bases and other resources. To meet the requirements of constructing "a high-level university" and "a double first-class university", the College of Public Administration gives full play to the comprehensive advantages of multiple disciplines, promotes the fusion of specialties, strengthens the integration of resources, improves the support of elements, builds a comprehensive practical teaching platform for public management, carries out in-depth case teaching, innovation training, investigation practice and comprehensive training, and strengthens the cultivation of skills for innovative governance.

\section{ANALYSISOFTHENEEDSANDIDEASOFTHE PRACTICAL TEACHINGSYSTEMREFORMFOR PUBLICMANAGEMENTSPECIALITIES}

\subsection{Study and Judgment on Reform Needs}

As reported by the follow-up survey on graduates of "Public Affair Management" in the past ten years, about one third of them take up an occupation in public sectors, less than 5\% started an undertaking independently, and more than half are engaged in other fields rather than the public sector. It seems to us that the external reasons for those figures are the system of "every entry through examinations" implemented by the government and public institutions, and insufficient talent absorption caused by the social organization development lag. However, if you dig deeper, you' 11 find that the current new economic and social development situation, the complexity of society management problems and the variability of external environment have put forward a higher request to public management talents, and the existing talent training mode cannot adapt to and promote the development of new technology, new industry, new format and new economy [3].The practical teaching reform of public management should be based on high-level employment application, and aims at working out solutions to improve students' core competitiveness, expand the employment scope, prevent the disconnection of theoretical teaching and practical teaching, and promote the systematic integration of knowledge and ability training [4]. Specifically, the practical teaching system reform of public administration specialties of Fujian Agriculture and Forestry University should satisfy the following requirements: Firstly, to optimize practical teaching mode of public administration specialties, so as to make it conform to the development requirements of the times, solve the problems of teaching, practice and employment, and provide reference for the cultivation of high-level public management talents. Secondly, to design a practical curriculum system emphasizing knowledge, ability and quality, which should not only 


\section{MEASURESOFPRACTICALTEACHINGSYSTEM REFORMOFPUBLICADMINISTRATIONSPECIALITIES INTHECONTEXT OFNOVELLIBERALARTS}

forward-looking and fundamental practice based on characteristics of the public administration specialties, so as to provide reference for the construction of practical teaching system and resource sharing of all liberal arts specialties in the school.

\subsection{Reform Ideas and Positioning}

Based on the above analysis of background and needs, it can be concluded that the general idea of the reform is to give full play to the development characteristics of the public administration specialties of Fujian Agriculture and Forestry University, closely focus on the needs of regional economic and social development for talents, fulfill the requirements of constructing "a high-level university" and "a double first-class university", take advantage of comprehensive superiorities of multiple disciplines, promote the fusion of specialties, strengthen the integration of resources, improve the support of elements, and build a comprehensive practical teaching platform for public management under the guidance of cultivating high-level and applied public management talents with complicate skills and innovative mind. The general requirements of the reform include sticking to the major direction of cultivating "public management" talents, consolidating the foundation for development and fostering the comprehensive thinking ability of talents under the guidance of "public spirit", and improving their innovation ability and professional qualities on the basis of "governance capacity". The general measures of the reform include: with optimizing the professional talents cultivation plan as the basis, building the teaching experiment and practice platform as well as developing the specialties comprehensive practice platform as the core support, lifting the innovative guidance ability of teachers as the key point, improving the design of practical teaching mechanism as the guarantee, to establish a practical teaching system aiming at cultivating high-level and applied public management talents.

\subsection{Optimization of the Professional Talents Cultivation Plan}

Combining with the discipline development frontier and local characteristics, and as required by the novel liberal arts, the professional talents cultivation plan is optimized to achieve the goal of cultivating "creative entrepreneurial type talents". The optimized plan highlights the new ideas, new technologies, new methods and new models introduced, and provides guidance and compliance for the top-level design of practical teaching system. Courses and projects of practical teaching system with different levels categories should be designed according to the organic relation and progressive relation of practical skill training.

\subsection{Construction of Teaching Experiment and Practice Platform}

The Liberal Arts Experimental Center of Fujian Agricultural and Forestry University under construction provides an opportunity for establishing a practical teaching system that combines with the theoretical course learning, with the professional laboratories and training bases as the carriers, the core course practical training projects as the basic content, and special virtual simulation projects as the benchmark. A system of practical training projects (simulation projects) for relevant specialties that includes "urban and rural community work training, digital urban grid management (GIS) training, e-government and collaborative office training, labor and social security training, and crisis emergency decision-making training modules" can be preliminarily set up. The construction of the platform should use the Internet information technology, combine thinking methods of department of scienc 、 critical thinkingand engineering with liberal arts practice, and integrate the training of "engineering thinking"、 critical thinking with the development of comprehensive decision-making and analytic consulting abilities of public management, and the system implementation and operation ability [5]. 
situational learning of students.

\subsection{Development of the Comprehensive Practice Platform}

Specialties

The comprehensive practical teaching links are designed, the public management simulation sand table competition is promoted (CLAP public management simulation sand table confrontation platform), the professional integrated skills assessment system is constructed, the administrative comprehensive vocational ability training plan based on quality assessment is made, and the off campus comprehensive social scientific research and service practice activities are carried out, so as to provide systematic, compound and cross domain comprehensive training and practice for students, and enhance their professional integrated skills and practical ability. To fulfill the requirements of promoting the modernization of national governance system and governance capacity, implement the school-running concept of "serving the grassroots and focusing on agriculture, rural areas and peasants", and achieve the goal of cultivating "elites of local governance and pioneers of green innovations", a practical teaching system with characteristics for the integrated management of the public sector, construction of urban and rural grassroots, and ecology and environmental management is established.

\subsection{Lifting the Innovative Guidance Ability of Teachers}

New requirements for improving skills of teachers of public administration specialties in the context of novel liberal arts are discussed and summarized concisely through extensive research and in-depth study, so as to achieve the self-improvement of teachers and promote the reform of application-oriented practical teaching methods and means. The strategy of "inviting experienced teachers to give lectures in the school and having teachers to take part in training and study outside the school" should be implemented to lift the ability of teachers. Teachers are arranged to conduct investigation and research in domestic first-class public administration disciplines, experts from the public sectors are hired to provide guidance to teachers of the school, and backbone teachers of all disciplines are appointed to systematically study the cultivation methods. It is important to explore and promote the "practical teaching" method in combination with internet information technology, and encourage the network teaching aid means to expand the coverage of "mixed teaching". Besides, teachers should take lead in the participatory learning, experiential learning and

\subsection{Improving the Design of Practical Teaching Mechanism}

It is necessary to clarify the responsibilities of teaching departments of the College, specialty teaching units, teachers of practical course and other main bodies, and establish a multi-body communication and consultation mechanism, thereby forming a joint force of practice and collaborative education. A scientific incentive mechanism for the evaluation of practical innovation is formulated, the incentive mechanism for teachers aimed at improving the effect of practical innovation education is optimized, and a practical teaching effect evaluation system for employment is established. A mechanism to promote the integration of theoretical knowledge and cases v practical courses and practical training projects is explored, so as to build a platform for students to improve their integrated skills. In addition, the industry-university-institute cooperation is strengthened and new channels for the construction of practice systems are expanded [6].

\section{CONCLUSION}

Our country has made continuous efforts to deepen the higher education reform in recent years, and the novel liberal arts construction aims at building a system that can cultivate high-level liberal arts talents with Chinese characteristics, and improving the quality of liberal arts talents training comprehensively [7]. The effective way to achieve the goal of training high-level and applied public management talents with complicate skills and innovative mind is carrying practical teaching throughout the whole process of personnel cultivation. Colleges and universities still pay much more attention to scientific research and theories than to teaching and practice. What we should do is to accelerate the transformation and attach much importance to teaching, especially practice teaching. The practical teaching reform of public administration specialties should actively take on the mission given by the times and be promoted in an all-round and systematical way through analyzing the current teaching situation and the requirements of talents training by novel liberal arts, clarifying the modules of 
capacity building, and strengthening the integration of channels, resources and elements.

\section{ACKNOWLEDGMENT}

This paper was the present achievement of the study on the practical teaching reform of urban management courses aiming at cultivating governance ability(No.201901212003), an industry-university collaboration education project of the Ministry of Education in 2019.

\section{REFERENCES}

[1] Wu Yan. First-rate university, first-rate speciality and first-rate talents[J], China University Teaching, 2017(11):4-12+17.

[2] Ma Mengchun. Research on the construction of public administration discipline[J]. Modern Economic Information, 2018(11):428.

[3] Yan Bing, Zheng Keling, Shi Chunyuan. Optimization of the training mode of public management talents in the context of New Liberal Arts[J]. Economic Research Guide,2019(17):92-94.

[4] Fu Jixiang. Construction of practical teaching system of public management major[J]. Education and Teaching Forum,2013(05):178-180.

[5] Yu Yong, Li Wanlian. Public management case teaching and critical thinking ability training[J]. Changjiang series,2018(30): 157.

[6] Wang Yongming, Gan Yuewen. On the construction of practical teaching system of public management[J]. Journal of Inner Mongolia Normal University(Education Scinece Edition),2015(09):156-158.

[7] Fan Liming, Yang Canming et al. Connotation and development path of new liberal arts construction[J]. China Higher Education Research, 2019(10):10-13. 